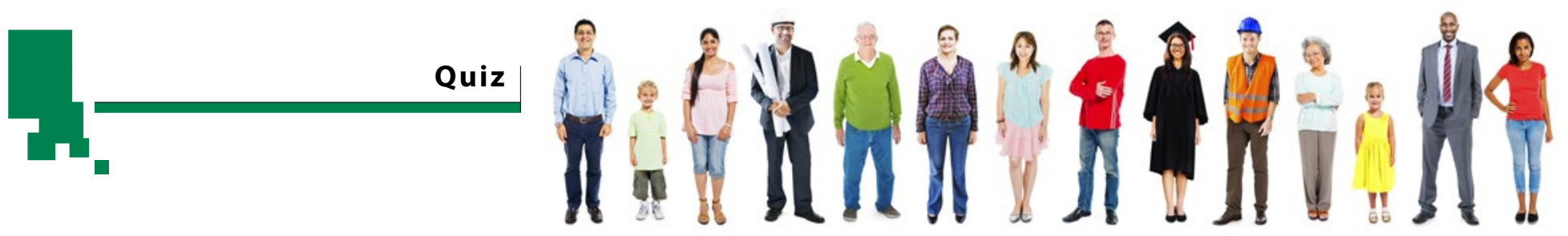

\title{
Zu oberflächlich?
}

Weil Menschen onkologische Wirkstoffe zum Teil sehr unterschiedlich verstoffwechseln, können auch die jeweiligen Wirkungen und Nebenwirkungen von Patient zu Patient variieren. Um diese Varianz etwas auszugleichen, wird die Medikamentendosis häufig anhand der Körperoberfläche (KOF) festgelegt. Allerdings: Es gibt unterschiedliche Ansätze, die KOF zu berechnen. Auch stellen einige Onkologen infrage, ob die KOF überhaupt die beste Möglichkeit darstellt, die Dosis festzulegen. Andere Patientenmerkmale (wie etwa bestimmte genetische Marker) könnten ggf. eine genauere Dosierungsgrundlage bieten.

Moritz Borchers
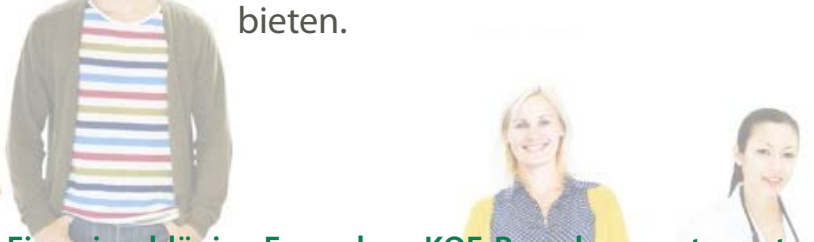

Eine einschlägige Formel zur KOF-Berechnung stammt von Delafield und Eugene $\approx=\mathrm{A}$ Dubois - in welchem Jahr wurde die Formel erstmals publiziert?

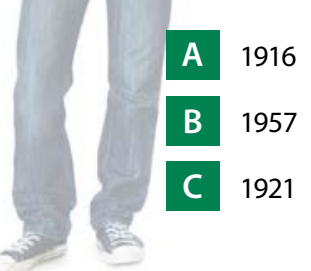

Der Buchstabe der richtigen Antwort ist

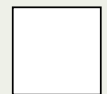

Name

Straße, Nr.

PLZ, Ort

Was ich noch sagen wollte...

Coupon bitte ausfüllen und abschicken an

Springer Medizin Verlag $\mathrm{GmbH}$

Redaktion Im Focus Onkologie - Quiz 11/2016

Aschauer Straße 30, 81549 München

Oder senden Sie uns eine E-Mail an doris.berger@springer.com

Einsendeschluss: 12.12.2016

\section{Und das können}

Sie gewinnen ...

Alles, was Wissen schafft.

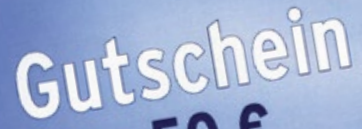
uber $50 €$

Q SpringerMedizin

Lösung des Quiz 9/2016 Richtig war: B

Unter den richtigen

Einsendungen verlosen wir drei Gutscheine über 50 Euro, die Sie für ein beliebiges Springer-Buch einlösen können.

Die Gewinne gehen an:

K. Wappler, Mildenau

K. Fritsch, Schmalkalden

R. Juncken, Berlin

Herzlichen Glückwunsch! 